\title{
Limb salvage in epithelioid sarcoma like hemangioendothelioma invading femur mid shaft: a case report
}

\author{
Chinder PS ${ }^{1}$, Samorekar BS ${ }^{2}$, Krishnamoorthy $\mathbf{N}^{3}$, Rangaswamy B.T ${ }^{4}$ \\ ${ }^{1}$ Dr. Pramod S. Chinder, M.S (Ortho), Fellow in musculoskeletal oncology, Consultant Orthopaedic Oncosurgeon, M.S. \\ Ramaiah Medical College, Bangalore, Healthcare Global Enterprises Ltd., Bangalore, ${ }^{2}$ Dr. Bheemsingh Samorekar, \\ MBBS, D’Ortho, Resident in Department of Orthopaedics, M.S. Ramaiah Medical College, Bangalore, ${ }^{3}$ Dr. Naveen \\ Krishnamoorthy, M.D (Pathology), Consultant Pathologist, Healthcare Global Enterprises Ltd., Bangalore, ${ }^{4}$ Dr. \\ Rangaswamy B.T. , MBBS
}

Address for Correspondence: Dr. Bheemsingh Samorekar, Email:bheemsinghvs@gmail.com

\begin{abstract}
Epithelioid sarcoma like hemangioendothelioma (ES-H) is recently added vascular soft tissue tumor in WHO list, with high propensity for infiltrative growth, local recurrence and low metastatic potential. We present a twenty year old male with right mid thigh swelling with pain since five months whose x-rays showed osteolytic, scalloped lesions of mid shaft femur. On workup was diagnosed ES-H for which wide excision of tumor was done and limb salvaged with biological reconstruction using free vascularised fibula.
\end{abstract}

Keywords: Epithelioid Sarcoma Likehemangioendothelioma, Femur, Immunohistochemistry, Limb Salvage.

\section{Introduction}

Epithelioid sarcoma like hemangioendothelioma also called pseudomyogenic hemangioendothelioma [1] is a vascular soft tissue tumor recently added in WHO classification of tumors and is of intermediate grade[2]. More common in young males and has high propensity for local infiltration and recurrence with low metastatic potential [3]. It usually arises from peripheral blood vesselsof soft tissue along with viscera, head, chest wall, abdominal wall, genital region, extremities $[4,5,6]$. Its differential diagnosis are epithelioid sarcoma, hemangioendothelioma, angiosarcoma and can be differentiated by immunohistochemistry being CD31 positive andCD34,EMA negative[7,8,]. Most surgically treated tumors by curettage alone had recurrence and ended in amputations [9]. Bony infiltration is also reported in femur, tibia, forearm, hand bonesand even spine $[5,10]$.

\section{Case Report}

A twenty years old male presented to orthopaedics OPD with complaints of right mid thigh swelling and pain since five months without any history of trauma, fever,

Manuscript received: $14^{\text {th }}$ Aug 2015

Reviewed: $30^{\text {th }}$ Aug 2015

Author Corrected: $7^{\text {th }}$ Sept 2015

Accepted for Publication: $18^{\text {th }}$ Sept 2015 loss of weight or any other such swellings elsewhere in the body. Pain was aggravated on weight bearing since one month. Local examination of right lower limb revealed irregular, multiple, tender swellings palpable over right mid thigh anterolaterally. No inguinal lymph node enlargement or engorged veins were found.

Hip and knee range of motion were normal. X-rays A P and lateral [Figure1] showed three osteolytic and scalloped cortical lesions, two in mid shaft femur anteriorly and another beneath it anterolaterally. Routine blood investigations were within normal limits. MRI right thigh plain and contrast [Figure(s)2A,2B] showed about 4 in number, $\mathrm{T} 1$ isointense and $\mathrm{T} 2$ hyperintense, enhancing lesions of vastus intermedius inanterolateral compartment, scalloping and destructing underlying bone's both cortices and showing intramedullary extension into femur. Largest among them measuring $50 \times 30 \times 18 \mathrm{~mm}$.

Jamshidi needle biopsy of swellings with histopathological examination showed malignant spindle cells having eosinophilic cytoplasm and immunohistochemistry [Figure3] showing strongly positive for CD31, FL1, cytokeratin, vimentin, focally positive for Bcl-2 and negative for SMA, S100 protein, CD34, CD99, proliferative marker Ki-67 has labelled Available online at: www.ijmrr.in 906 | P a g e 
$5 \%$ of tumor cells favoring a diagnosis of epithelioidsarcoma like hemangioendothelioma. Hence to rule out any other lesions elsewhere whole body3DPET-CTscan [Figure(s)4A,4B] was done, which showed metabolically active, punched out osteolytic lesions with avid FDG uptake, but no pulmonary/distal metastasis. With all the above reports, case was discussed intumorboard and was decided to salvage the limb.

Wide excision of tumor done along with biological limb reconstruction using free vascularized fibula from contralateral leg and the excised femur was used after extra corporeal radiotherapy (ECRT) asstrut graft over the fibula and fixed with custom made titanium plate with bone allograft paste applied at excised ends [Figure5].

HKAFO (Hip knee ankle foot orthosis) was used for femur stability post operatively. Physiotherapy included hip and knee range of motion exercises along with moderate quadriceps /hamstrings strengthening exercises after two weeks post-op along with non weight bearing walk with walker for six months. Excised tumor tissue histopathology and immunochemistry showed circumscribed neoplasm with spindle cells arranged in vague fascicles, neoplastic cells have eosinophilic cytoplasm and express CD31, FLI-1, cytokeratin and negative CD34 confirming the diagnosis of Epithelioid sarcoma like hemangioendothelioma.

Post-op x-rays taken on $1^{\text {st }}$ post-op day, 6,12 and 24 months follow-up [Figure 6] showed acceptable implant position and free fibula with signs of graft acceptance and viability.

At 18 months follow-up [Figure7] there were no signs of tumor recurrence and patient was walking full weight bearing unaided with normal hip ROM but knee stiffness for which cyclic passive motion(CPM) was advised.

At 24 months follow-up knee ROM had improved, quadriceps and hamstrings strengthening exercises were advised for thigh muscles hypotrophy.

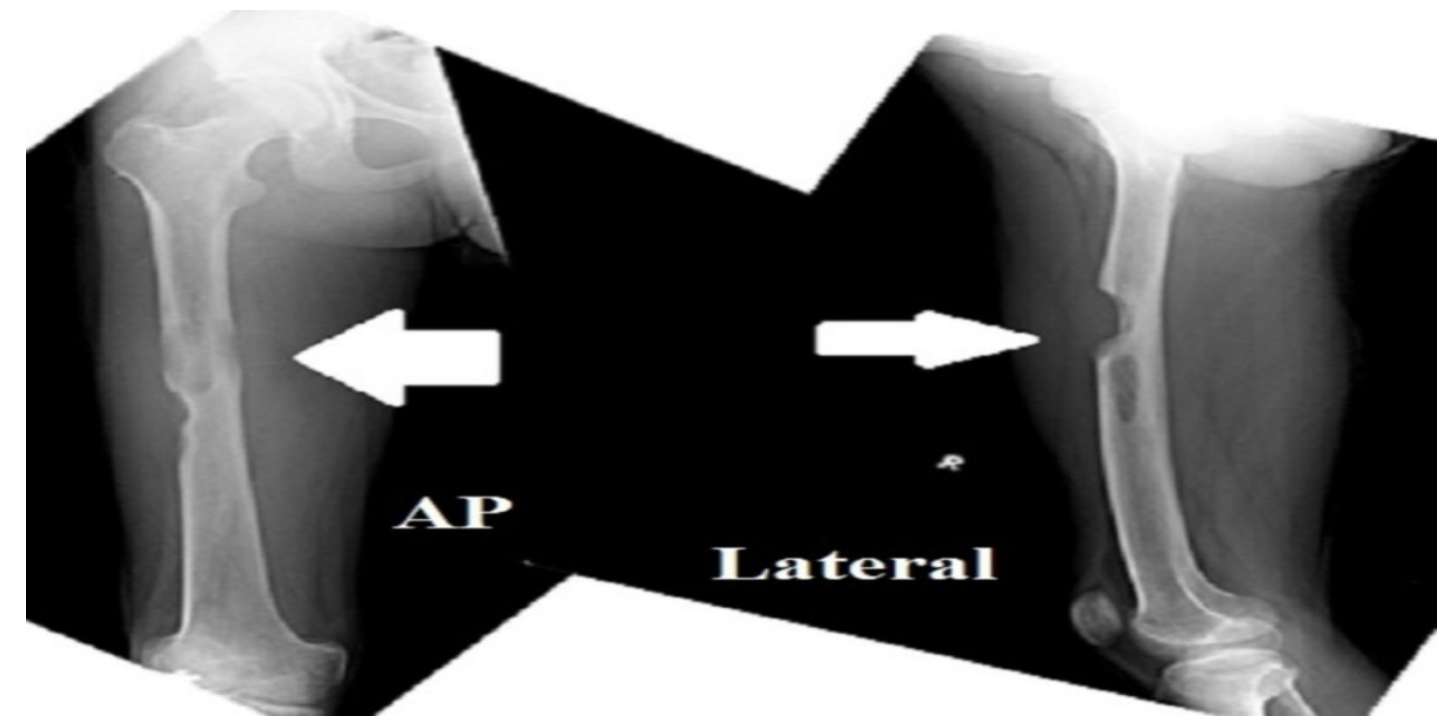

Figure 1: x-ray right femur showing osteolytic, scalloped lesions in mid shaft anteriorly and anterolaterally. 


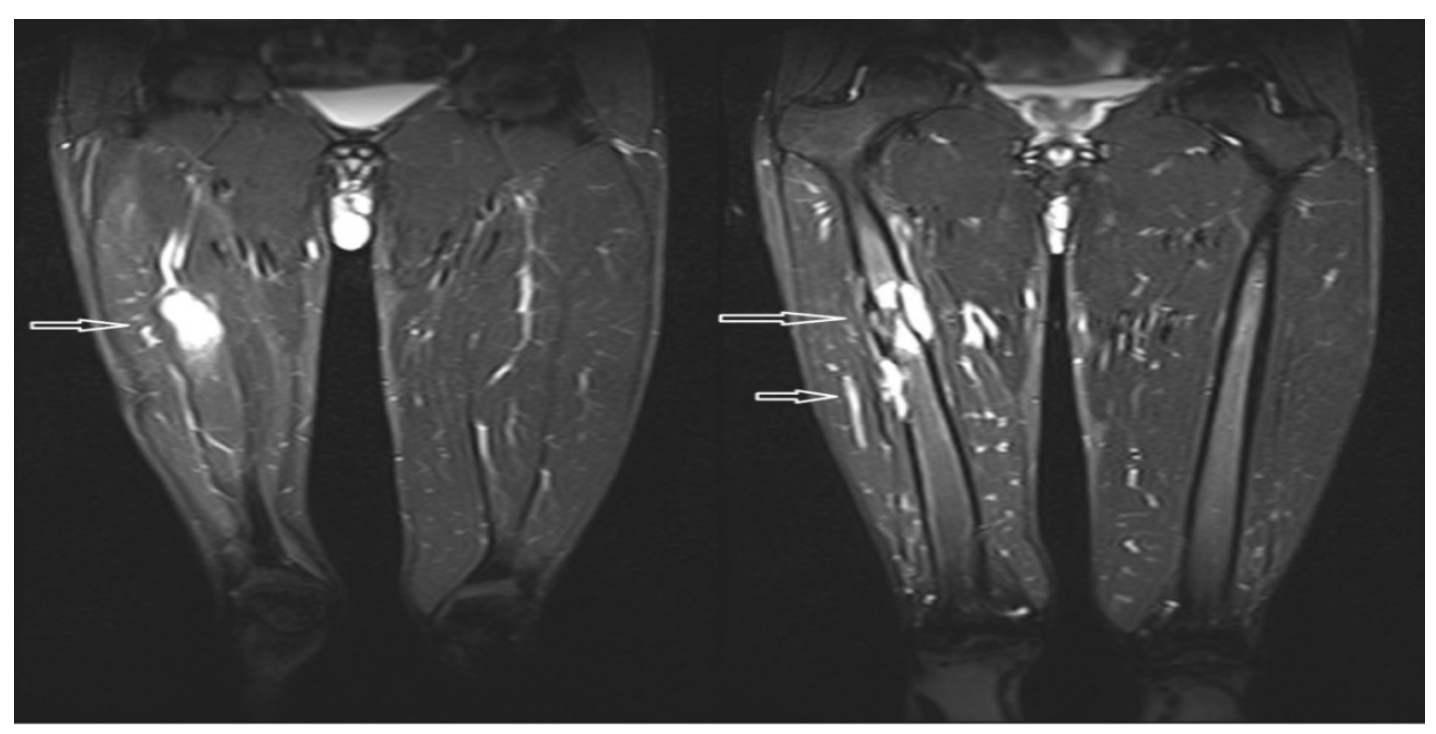

Figure 2A : MRI right thigh unenhanced T1W axial section showing hypointense lesion in the anterolateral aspect of mid thigh involving vastus intermedius and causing scalloping and destruction of outer and inner anterior cortex of mid shaft femur with intramedullary extension.

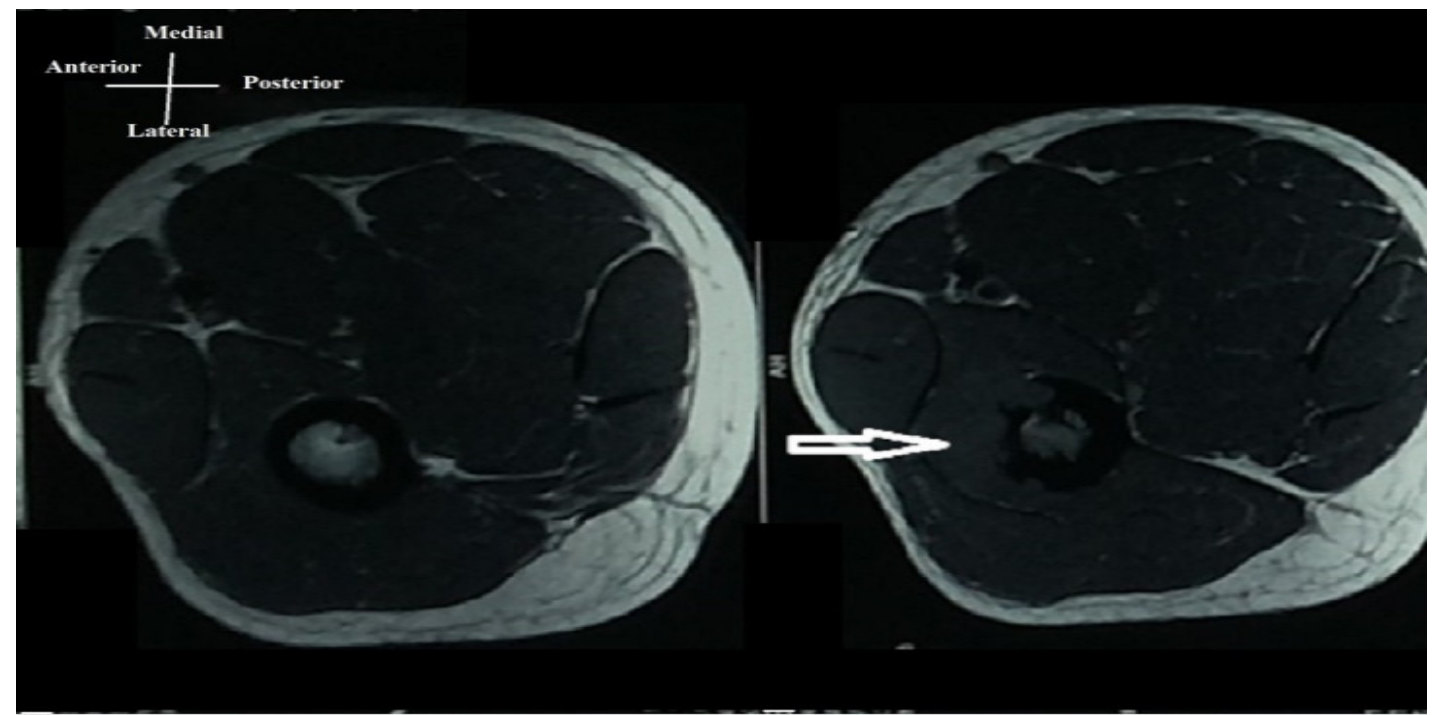

Figure 2B: MRI right thigh post contrast T1W transverse section showing intense enhancement of lesion with enhancing intramedullary component. 


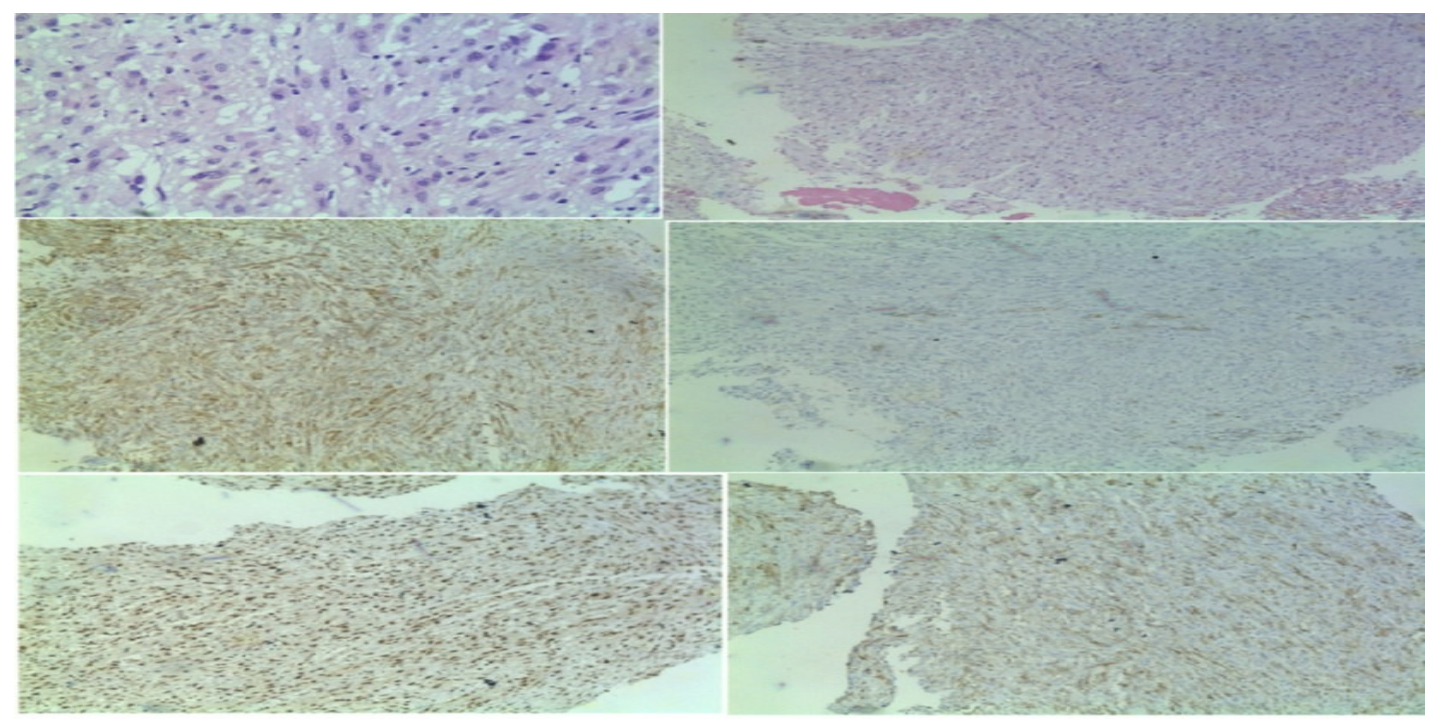

Figure 3 : Histopathology and Immunohistochemistry showing -A) High power(40x) view showing spindle to epithelioid cells with abundant eosinophilic cytoplasm with many having intracytoplasmic vacuolations suggestive of vascular differentiation, B) Low power(10x) view showing sheets and vague fascicles of cells,C) Strong expression of FLI-1,D) Negative for CD34,E) Strong expression of Cytokeratin,F) Moderate expression of CD31.

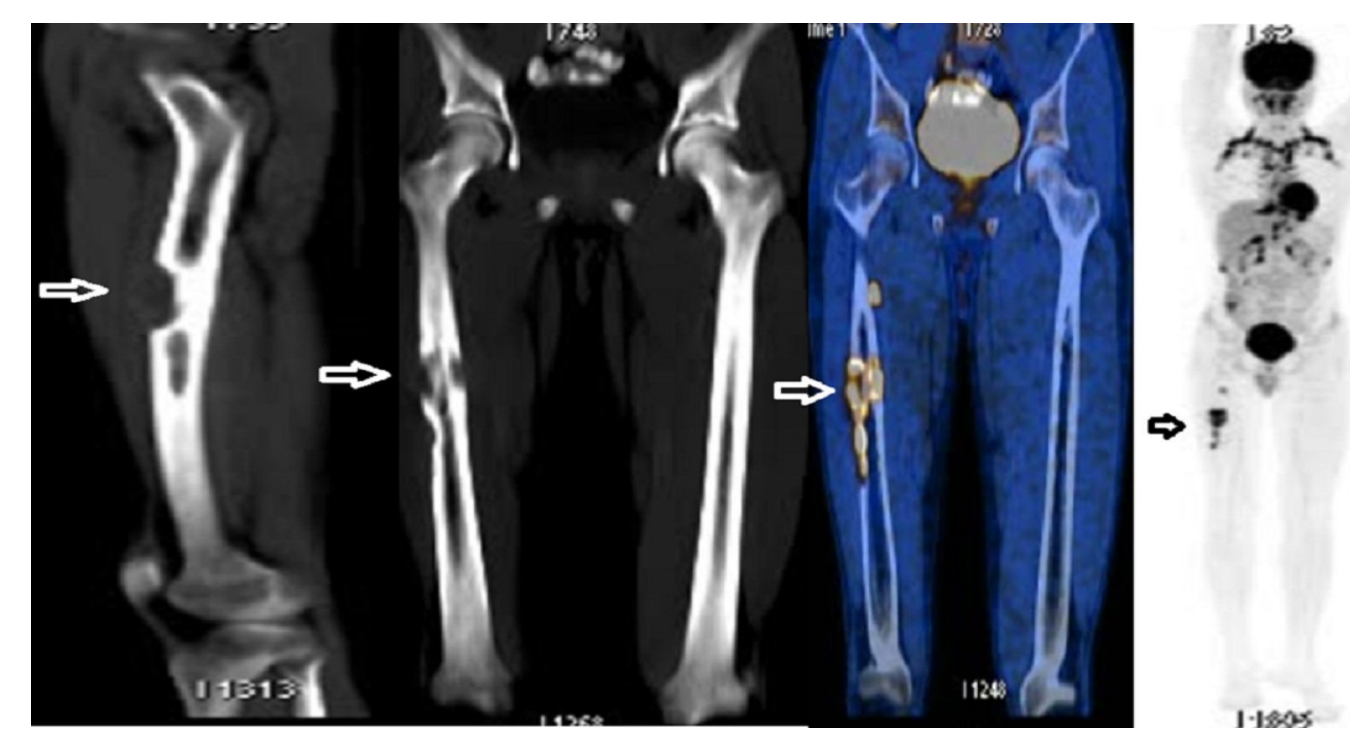

Figure 4A: Whole body 3D PET-CT showing metabolically active, punched out osteolytic lesions in right midshaft femur with avid FDG uptake. (Normal FDG uptake seen in brain, heart, kidneys, urinary bladder) 

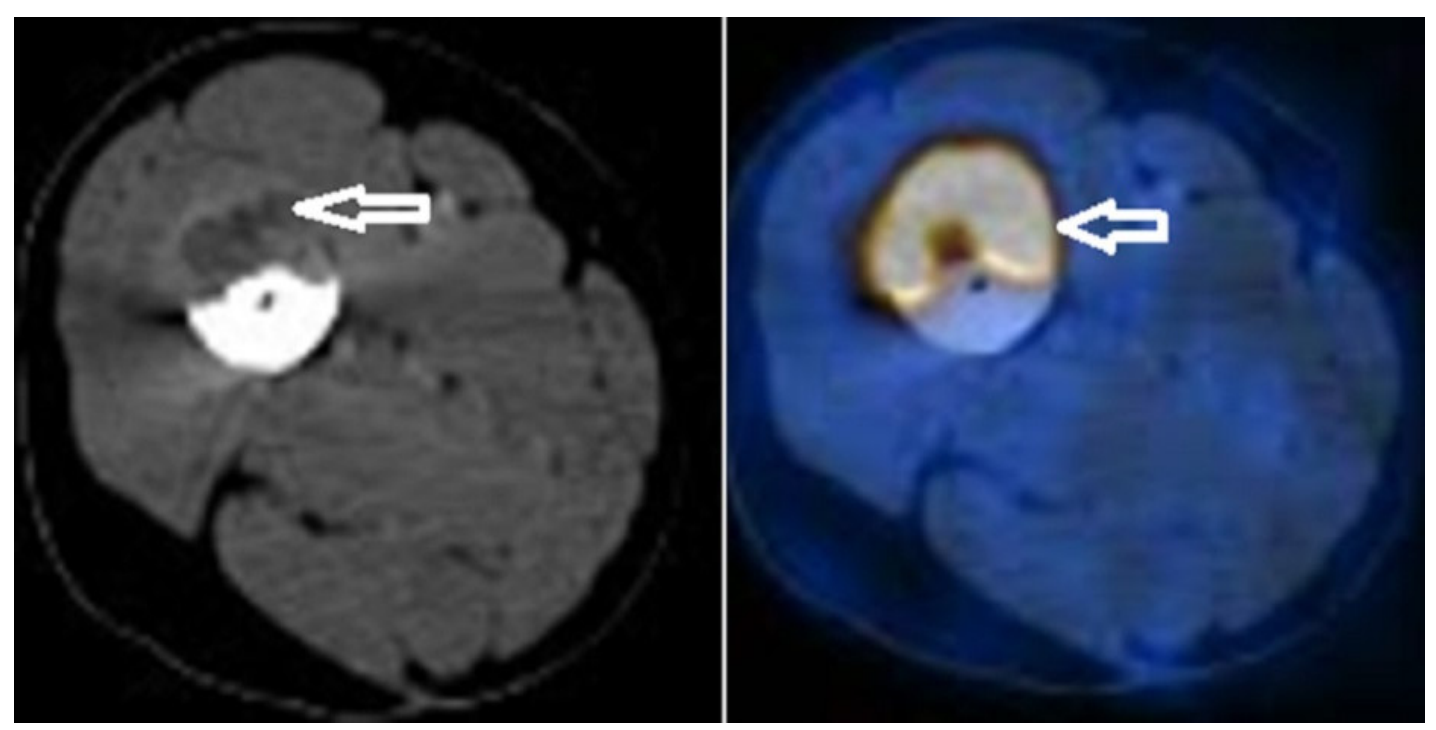

Figure 4B: Right mid thigh 3D PET-CT showing vastus intermedius mass extending into femur medullary canal anterolaterally with FDG uptake.
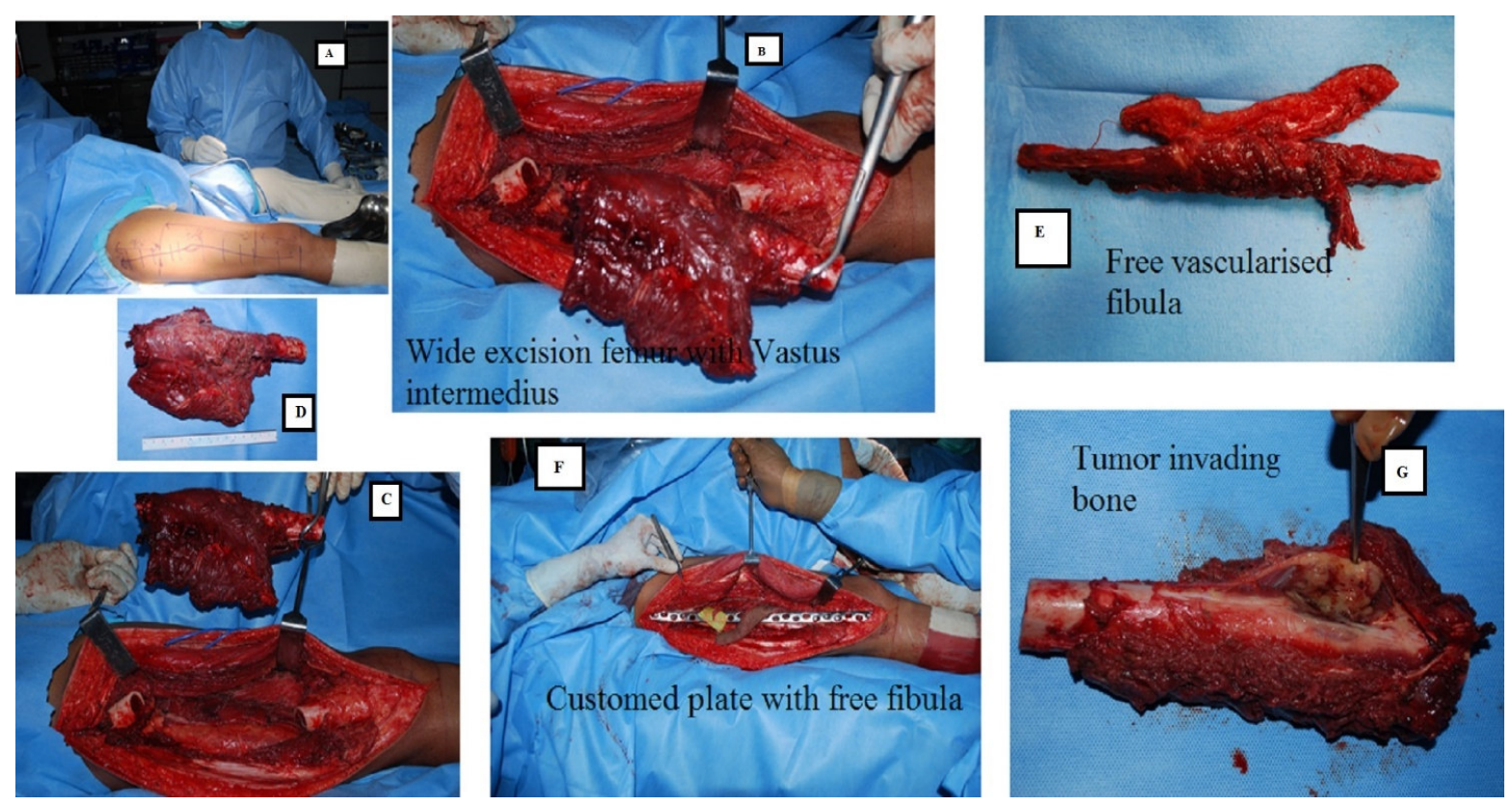

Figure 5: Intraoperative pictures showing, $A$ : pre-operative skin markings over right thigh, $B / C / D$ : about $20 \mathrm{~cm}$ mid shaft femur wide excision along with surrounding muscles mainly vastus intermedius, E: Free vascularised fibula from opposite leg, F: free fibula fixed along with excised femur hemi-shaft(after ECRT) using custom made titanium plate, G: greyish white, lobulated, firm consistency mass of size $4 \times 4 \times 1 \mathrm{~cm}$ invading medullary canal. 


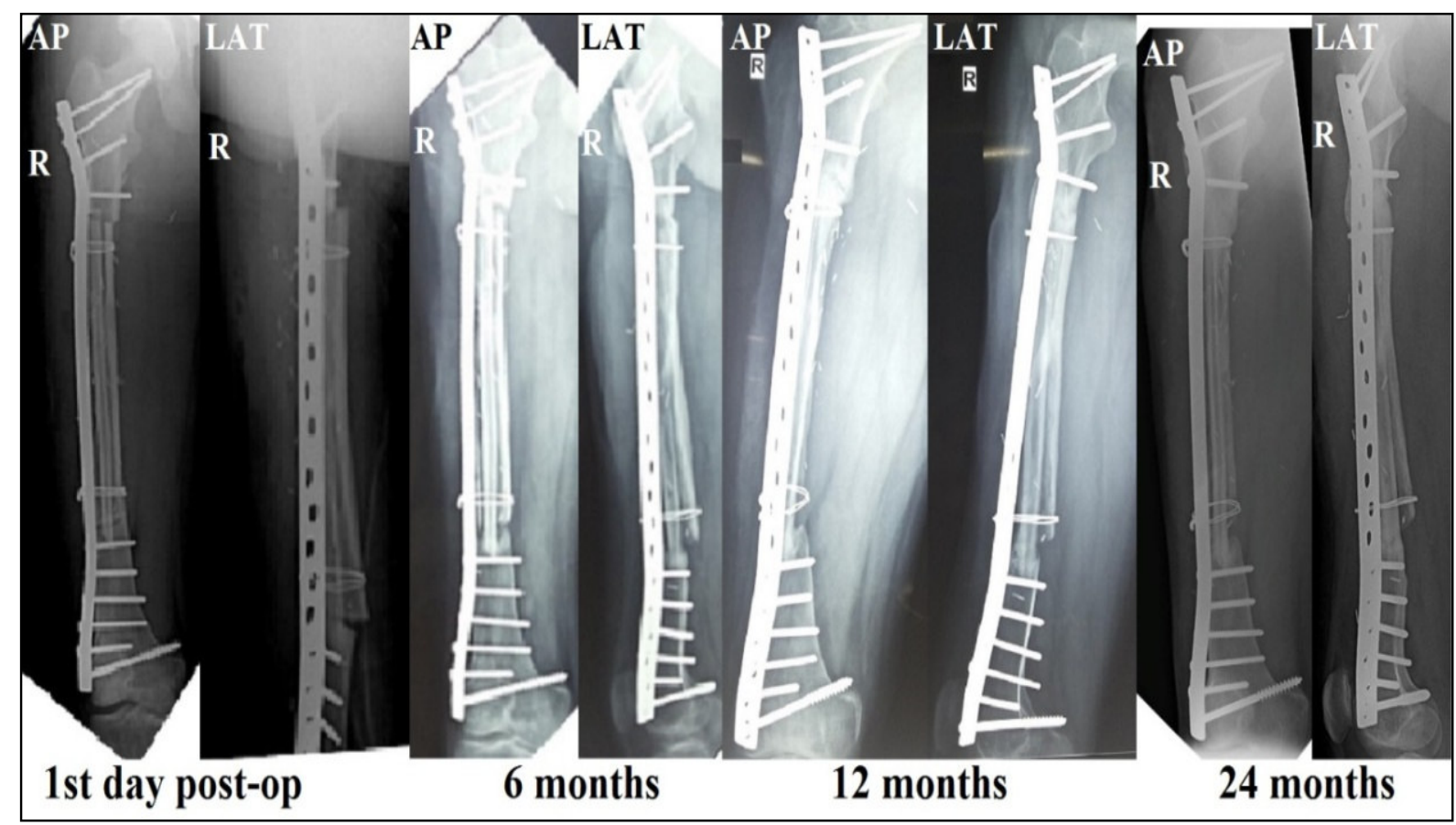

Figure 6: Immediate post op x-ray right femur showing good graft position and acceptable implant fixation. 6, 12 and 24 months post op X-rays show graft acceptance signs along with well maintained plate fixation.

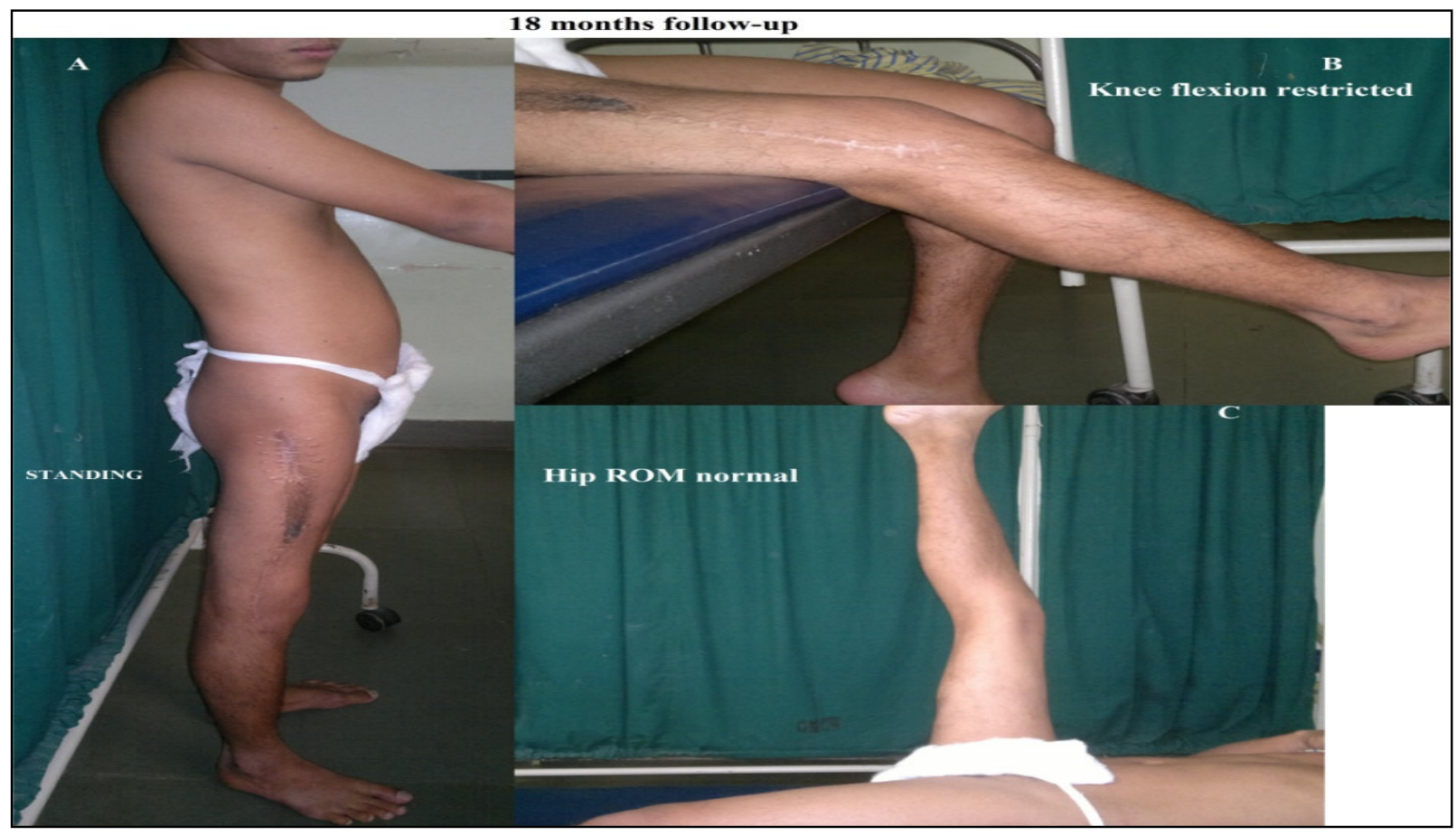

Figure 7: 18 Months follow-up pictures showing patientstanding(A) fullweight bearing, unaided with normal hip range of motion(C) and knee stiffness(B). 


\section{Discussion}

Luis Requena et al [8] in their study described ES-H in brief as a dermal and soft tissue neoplasm common in young adult males(4:1) in distal extremities with growth pattern of poorly demarcated nodules and fascicles.

Histology of mild cytologic atypia with no evident vasoformation and immune statins positive for cytokeratin AE1/AE3, CD31, FLI-1, ERG and INI-1; negative for EMA and $\mathrm{CD} 34$, cytogenetics of $\mathrm{t}(7 ; 19)(\mathrm{q} 22 ; \mathrm{q} 13)$. Treatment being surgery with frequent recurrences, mild malignancy $(<7 \%$ of patients with metastases).

Though Billings et al. first described it in 2003; only 12 cases are reported as per our literature search with only study of Ahmet et al. and Friel N.A. et al. showing the treatment and its follow up results.

Friel et al [9] had operated with endoprosthesis after wide resection of ES- $\mathrm{H}$ proximal femur which was misdiagnosed earlier as slipped capital femoral epiphysis (SCFE) and shown no recurrence at 9 months follow up.

Ahmet et al [2] had managed a right index finger middle phalynx diagnosed as ES-H with complete excision of tumor, but at 7 months ray amputation was done for recurrence.

Amary M. Fernanda et al [6] have described in their 5 cases regarding ES-H about high chances of local recurrence which ended in amputation finally.

Akiko Watabeet al [4] reported ES-H in right index finger, dorsum hand and forearm in same patient showing multifocal occurrence.

ES-Hof thoracic spine treated by macroscopic excision has also been reported recently and has warranted adjuvant therapy[10] Foremost importance is to accurately diagnose by histopathology and immunohistochemistry by a specialist pathologist as resembling features are also seen in epithelioid sarcoma, hemangioendothelioma, angiosarcoma, fibrosarcoma[8].

\section{Conclusion}

Though ES-H is an intermediate grade tumor known for local recurrence with no reports of distant metastases till now, its better to surgically manage by wide excision of tumor and salvage the limb depending on the tumor site.

The authors declare that they have no competing interest. Written informed consent was obtained from patient for publication of this case report and accompanying images.

\section{References}

1. Hornick JL, Fletcher CDM. Pseudomyogenic hemangioendothelioma: a distinctive, often multicentric tumor with indolent behavior. Am J Surg Pathol [Internet]. 2011 Mar;35(2):190-201.

2. Karakasli A, Karaaslan A, Erduran M, Capkin S, Tuna EB, Havitcioglu H. Pseudomyogenic (Epithelioid sarcoma-like) hemangioendothelioma with bone invasion. $\mathrm{J}$ Orthop [Internet]. Elsevier Ltd; 2014;11(4):197-9.

3. Billings SD, Folpe AL, Weiss SW. Epithelioid sarcoma-like hemangioendothelioma. Am J Surg Pathol. 2003;27(1):48-57.

4. Watabe A, Okuyama R, Hashimoto A, Hosaka M, Hatori M, Kariya Y, et al. Epithelioid sarcoma-like haemangioendothelioma: A case report. Acta Derm Venereol. 2009;89(2):208-9.

5. Tokyol C, Uzüm N, Kuru I, Uluoglu O. Epithelioid sarcoma-like hemangioendothelioma. 2005;(18):436-9.

6. Amary MF, O'Donnell P, Berisha F, Tirabosco R, Briggs T, Pollock R, et al. Pseudomyogenic (epithelioid sarcoma-like) hemangioendothelioma: Characterization of five cases. Skeletal Radiol. 2013;42(7):947-57.

7. Miettinen M, Fanburg-Smith JC, Virolainen M, Shmookler BM, Fetsch JF. Epithelioid sarcoma: An immunohistochemical analysis of 112 classical and variant cases and a discussion of the differential diagnosis. Hum Pathol. 1999;30(8):934-42.

8. Requena L, Kutzner H. Hemangioendothelioma. Semin Diagn Pathol. 2013;30(1):29-44.

9. Friel NA, Rothenberg AC, Weiss $\mathrm{K}$. Pseudomyogenic Hemangioendothelioma of Bone Initially Managed as Slipped Capital Femoral Epiphysis : A Case Report. 2014;(April):363-8.

10. McGinity M, Bartanusz V, Dengler B, Birnbaum L, Henry J. Pseudomyogenic hemangioendothelioma (epithelioid sarcomalike hemangioendothelioma, 


\section{How to cite this article?}

Chinder PS, Samorekar BS, Krishnamoorthy N, Rangaswamy B.T. Limb salvage in epithelioid sarcoma like hemangioendothelioma invading femur mid shaft: a case report. Int J Med Res Rev 2015;3(8):906-913. doi: 10.17511/ijmrr.2015.i8.168. 